\title{
The pilot study of SMART-Resilience a psycho-educational program
}

\author{
Kadek Suranata*) \\ Universitas Pendidikan Ganesha, Indonesia \\ *)Corresponding author, ఏe-mail: kadek.suranata@undiksha.ac.id
}

\begin{abstract}
They propose this pilot study is investigating the feasibility of the Smart-resilience program for secondary school students. The one group pretest and posttest experiment design conducted by involved 45 of second grades students of secondary school in Province of Bali, Indonesia as a participant. In each area of the urban, suburban, and rural schools comprise 15 students. The Indonesian version of a student's well-being scale used to collect the data for pretest and posttest assessment. General Linear Model of Repeated Measure ANOVA conducted on the analysis of the data through the JASP program. The results show; (1) Smart-resilience programs are effective to improve student well-being in overall school areas, (2) there are differences in the effectiveness for students in urban, suburb and rural school areas, (3) the programs achieve a high acceptance and accessibility by students and the school counselor.
\end{abstract}

Keywords: Counseling, resilience training, CBT, well being

How to Cite: Suranata, K. (2019). The pilot study of SMART-Resilience a psycho-educational program. COUNS-EDU: The International Journal of Counseling and Education, 4(3), 121-128. DOI: https://doi.org/10.23916/0020190424230

\section{Introduction}

In the industrial's era of revolution 4.0, every nation in the world requires developing the quality of its education, because the quality of education is one standard of prosperity in improving human capabilities in a country. In the last decade, it has charged that education is not just a matter of establishing knowledge oriented to cognitive aspects, but character is also very important. The cognitive aspects require students to gain new knowledge, while factors contribute to the process of students' success in their academics and lives (Durlak, Weissberg, Dymnicki, Taylor, \& Schellinger, 2011).

Predicted in about $20 \%$ of young people in the world, including students and colleges, experienced clinical depression and increased about ten times more than their 50s in the past (Lewinsohn, Hops, Roberts, Seeley, \& Andrews, 1993). In Indonesia, we can observe the symptoms of students' destructive behavior from the rise of news coverage in the media, electronic, and also through social media about teenagers, and students. This phenomenon is paradoxical because the current environment predicting be further established and advanced, sufficient food is available, better transportation, more suitable school facilities, technology, entertainment, more trendy or attractive clothes are usable (Mongrain \& AnselmoMatthews, 2012).

Stress and depression are among the highest risks that threaten failure in realizing student academic success (Dray et al., 2011; Martínez-Martí \& Ruch, 2017; Schulz et al., 2014). However, these conditions did not run parallel with achieving subjective well being and happiness in youths (Sagone \& Caroli, 2013; 
Sagone \& Elvira De Caroli, 2014). Students often face various difficulties, psychological constraints, and stress in carrying out their academic tasks and tasks in their development. Students who cannot overcome such problems are students who cannot actualize their resilience (Cutuli, Desjardins, et al., 2013).

The school counseling system at school is proposing to support students to develop the potential needed to produce optimal development. One aspect of the prosperous school counseling program is the support student to be wellbeing. To find that, they need to develop some non-cognitive abilities that cover all aspects of psycho-emotional that can save and show positive responses in handle of many conditions, both disappointment, hopelessness, stress, unfairness, and other conditions which threaten both at school and outside school (Suranata, Atmoko, Hidayah, Rangka, \& Ifdil, 2017).

Resilience programs are one of the forms of interventions to promote the psychological wellbeing of students. This program intervention has been formed in many countries in the world integrated into school education (Leppin et al., 2014; Waters, 2011). Resilience training programs in schools are an effective way to support the students to improve their skills required to avoid stress or depression. This program has also been used in overcoming problems with tobacco, alcohol, and narcotics addiction among students (Rebecca Kate Hodder et al., 2017). Empirical results of research on resilience programs such as those summarized in a meta-analysis study show that resilience programs gain acceptability as part of the curriculum in schools to establish psychological resilience and wellbeing (VicHealth, 2015). Meanwhile, in Indonesia intervention programs for resilience in school have not been examined.

Some resilience programs implementing in the schools were rising of large effectiveness from the view of later research results (Cutuli, Gillham, et al., 2013; Rebecca Kate Hodder et al., 2014). These models commonly are the focus on the cognitive-behavioral procedure. In comparison with that, the Smart-Resilience program test in this study was integrates CBT with the paradigm strength-based counseling approach. The Smart-Resilience is a psycho-educational program to improve the student potential to deal with obstacles so they can express psychological wellbeing. This program is designed for all students in schools. The program combines procedures and approaches in behavioral cognitive and strengths-based counseling. Cognitive-behavioral counseling (CBT) is the approach that focuses on mind experiences that affirm perception and resolve negative thoughts and maladaptive views that were original started by Beck (Suranata, Atmoko, \& Hidayah, 2017). While the strengths-based is a counseling paradigm that emerges from a positive psychology perspective oriented to the awareness of the sources of strength in students to overcome their obstacles (Bannink, 2014; Shoshani \& Steinmetz, 2014). This pilot study proposes to test the effectiveness and feasibility of the Smart-resilience program for secondary school students.

\section{Methods}

\section{Experimental design}

We performed this pilot study by an experimental with the one group pretest-posttest design. We selected 45 students from secondary school students in the Province of Bali as research samples determined by cluster random sampling. In each rural, suburb and urban school area it represents 15 students. This study also involved three school counselors to facilitate of carry out the program. Each group of respondents, rural, urban and suburban groups facilitating by one school counselor. Figure 1 shows the flow chart about the recruitment and retention subject also procedure of the experimental of this study.

\section{Instrumentation}

The 39 items of the Indonesian student subjective wellbeing scale collected the research data. Kurniastuti \& Azwar (2016) report that the quality of this scale has good validation for each item and reliability. Through paper and pencil based, students report their wellbeing conditions through each scale item. Students choose one of five alternative answers for each item, from which is not agreed (score 1) to great agree with (5). Under the experimental procedure used in this study, students of study participants took wellbeing measurements twice, before and after attending a counseling program as a treatment. They had got an explanation that the results have no impact on test their achievements in school. So they need not hesitate to answer according to their real condition. 


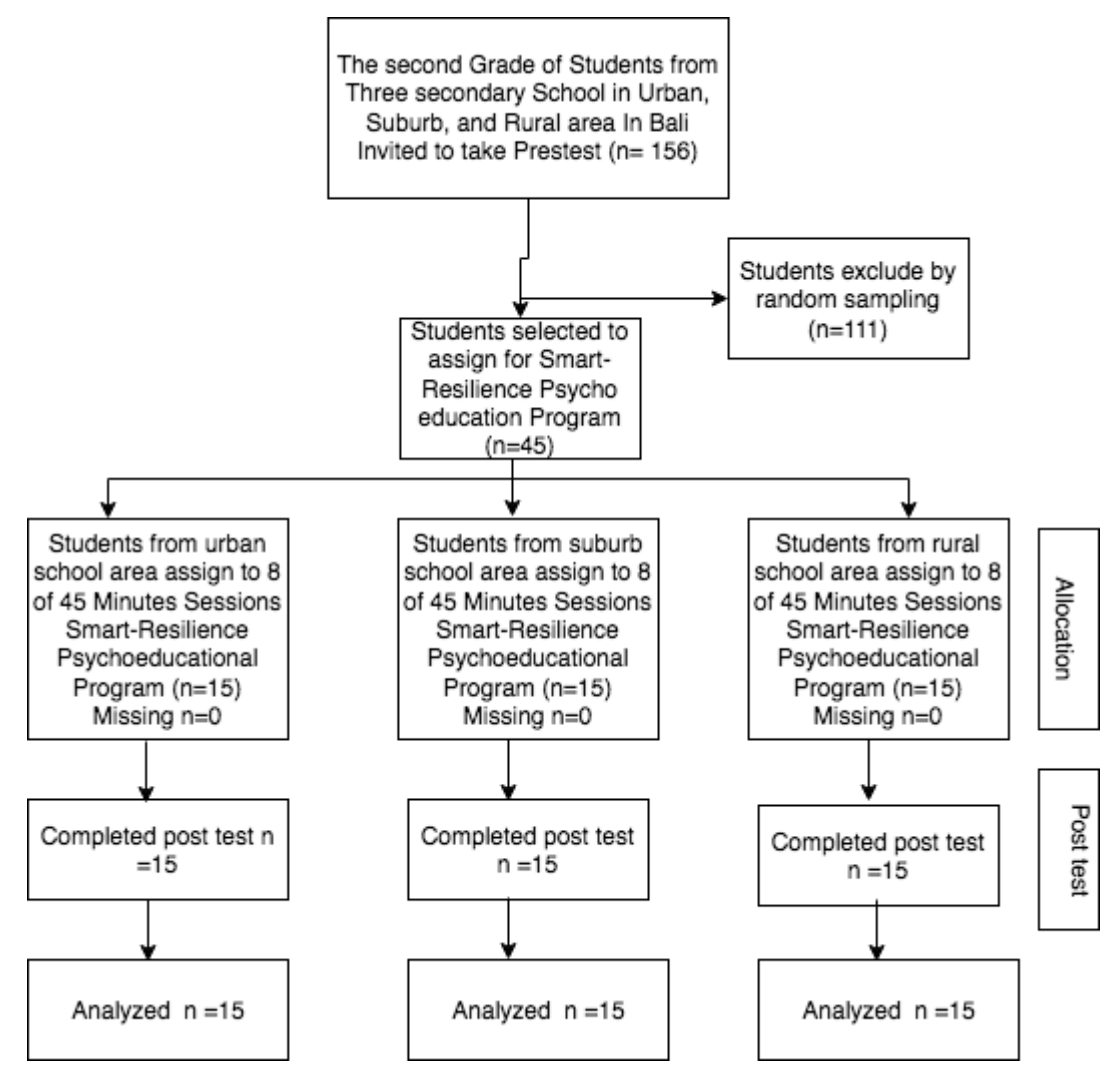

Figure 1.The recruitments and retention subject study

\section{Smart-resilience procedure}

The SMART-Resilience is a psycho-educational program carried out by linked the cognitive-behavioral and strengths-based counseling model. The strategy includes five stages, i.e. (1) Source your strengths, students coaching to establish and recover sources (internal and external that appear in themselves and in their surrounding); (2) Manage yourself, which is a step to establish, regulate the sources owned, which includes perceiving management, self-management, time management, money management and so on; (3) Actuating your potential, is a step to implement the resources owned to deliver psychological well-being; (4) Remember The God, is a step to train students to improve their spiritual side, affirming to their religion and beliefs; and (5) Take your Dream, is the final step to develop confidence, hope, and encouragement to reach its objectives and ideals.

There are several procedures applied in this model which comprise: (1) drawing and story, students draw themselves by pointing out their strengths both from within themselves and the assets gained from environmental support, along with the self-portrait, students also narrate the power resources it knows; (2) cognitive restructuring and positive affirmation, students manage beliefs and emotions, through recognizing and identifying sets of negative expectations and affections that occur within them, holding negative thoughts and feels, and changing with more adaptive forms of thought and feels; (3) selfmanagement, students manage themselves as an entity, from chance, resources had, covering economic. Self-management carries out by recording his activities, handling of chance, infrastructure, and finance in a Logbook. We decide the logbook every week, facilitated by the school counselor; (4) problem-solving training, a technique intended to train students to decide based on the best solutions they have; (5) social skills training, which is a technique to recover the quality of problem-solving related to social conflicts. We implement this technique using the psychodrama method; (6) miracle question, is a procedure take from the solution-focused brief therapy model (Dameron, 2016; Kim \& Franklin, 2009); and (7) we integrate Mindfulness technique on Cognitive Behavioral tradition (Cherkin et al., 2016).

\section{Data analysis}

The research hypothesis was tested through GLM RM-ANOVA. The analysis in this study involved 3 sample groups based on the school area (urban, suburban, and rural areas) and two-time observations 
(pretest and posttest). Analysis of research data was carried out using the JASP V. 0.10 statistic analysis program (Goss-Sampson, 2019). The main effect SMART-resilience is described from the resilience comparison at each observation time. The main effects on group differences and interaction effects between time and group were tested for the effect size on partial eta square (П2partial) that describes the proportion of total variables caused by the factors tested (Field, 2009). The level of significance used in this study was 0.05 (Hair, Black, Babin, \& Anderson, 2010). The data of respondents' perceptions on the feasibility of the program, including the obstacles experienced during the program were also narrated and discussed.

\section{Results and Discussion}

The effect of smart-resilience on students resilience

The results of the RM ANOVA report show an expansion in the average resilience from the baseline to the posttest in each group that shown in table 1.

Table 1. Mean and standard deviation on baseline and post-test in overall group

\begin{tabular}{llll}
\hline RM Factor 1 & Group* & Mean & SD \\
\hline \multirow{2}{*}{ Baseline } & 1 & 97.5 & 2.35 \\
\cline { 2 - 4 } & 2 & 99,75 & 4.82 \\
\cline { 2 - 4 } & 3 & 98.35 & 3.67 \\
\hline \multirow{2}{*}{ Post-test } & 1 & 163.8 & 2.75 \\
\cline { 2 - 4 } & 2 & 178.23 & 2.45 \\
\hline & 3 & 111.10 & 2.85 \\
\hline
\end{tabular}

*Group 1 urban, 2 suburbs, 3 rural

Table 2 showed that the main effects of time (pretest, posttest) for resilience were significant ( $\mathrm{F}$ [1, $42)=2667.63, p<0.05$, with effect sizes on $\rceil 2$ partial $=0.89$ ). Meanwhile, the interaction effect between $x$ time groups was significant $(F[2,42)=35.08, p<0.001$, with the effect sizes on 2partial $=0.75)$.

Results of RM ANOVA in Table 2 and Table 3 confirm the hypothesis tested in this study, that the Smart-resilience program is effective for students in the urban, suburb, and rural school areas. Effect size П2partial $=0.99$, which means is high of effect sized (Field, 2009). The results also prove that there are differences in the effect of this program for students in urban, suburban, again on rural areas at 12 partial = 0.75 , which measures it is high.

Table 2. Within subjects effect

\begin{tabular}{lllllll}
\hline & Sum of Squares & $\mathrm{df}$ & Mean Square & $\mathrm{F}$ & $\mathrm{p}$ & $\eta^{2} \mathrm{p}$ \\
\hline Time & 23158.84 & 1 & 2318.84 & 2667.63 & $<0.05$ & 0.89 \\
\hline Time vs group & 433.09 & 2 & 244.04 & 35.08 & $<0.05$ & 0.75 \\
\hline Residual & 367.09 & 42 & 10.05 & & & \\
\hline
\end{tabular}

Note. Type III Sum of Squares.

We can determine the comparison of effect among the three groups in the Post-hoc of Bonferroni analysis in Table 3. 
Table 3. Post hoc comparisons

\begin{tabular}{llllll}
\hline Groups & $\begin{array}{l}\text { Mean } \\
\text { Difference }\end{array}$ & SE & T & P bonf. \\
\hline 1 & 2 & -0.98 & 0.52 & -1.66 & $<.05$ \\
\hline 1 & 3 & 4.35 & 0.52 & 6.67 & $<.05$ \\
\hline 2 & 3 & 4.65 & 0.52 & 8.94 & $<.05$
\end{tabular}

*Group 1 urban, 2 suburbs, 3 rural

These results show that the program is more effective for students in suburb areas than in urban areas, but in students in rural areas, it is lower than in urban areas. This means that students in suburban groups get the highest effectiveness.

\section{The students and school counselor perception on feasibilities of smart-resilience}

The student groups in urban areas have completed the program in 3 months, for students in the suburbs for 2.4 months, and all students in rural areas complete the program longer than 3 months (3.9 months). All the student participants and school counselors involved to attend the program agreed that's the SmartResilience program had well acceptability and feasibility. This supported the results of statistic results shown that's the program was effective. They could attend their roles in the program. They agreed about the Smart-resilience procedure can do. About $90 \%$ of students in urban areas say they are able by implement the procedure and techniques after they end the program. There was $85 \%$ of students are in urban suburbs, and only $65 \%$ of students in rural areas say they can do the procedure well without the counselor's advice. About $95 \%$ of students in rural areas say that they only repeat several sections of the procedure of whole the program.

\section{Discussion}

The Smart-Resilience program is a recent model in school counseling intervention, which improved by changing the strength-based cognitive behavioral counseling models. Before being carried out in a further population, its efficacy and suitability must investigate, so we know it whether this method applies. According to the objectives of this research, we confirm the results that are the Smart-Resilience program were meet as an effective and feasibilities program. That's finding from statistic analysis occurs and the feasibilities perception from the participant.

This result of research in line with several past researches that have confirmed the effectiveness of the cognitive-behavioral model as interventions applied to enhance resilience among students or adolescents can meet in the results. Study of the Penn Resiliency Program or PRP in overall society (Challen, Machin, \& Gillham, 2014; Cutuli, Gillham, et al., 2013; Gillham et al., 2012; Rebecca K Hodder et al., 2012), which produces the effectiveness and feasibility of school-based resilience interventions through developing mental status and avoidance of emotional or behavioral troubles. Study of the effect of the Penn resilience program conducted in early adolescents in India has found successful in developing children's attribution of life events (Sankaranarayanan \& Cycil, 2014). Other resilience program models that investigate and have known effectiveness such as Ready (Burton, Pakenham, \& Brown, 2010). This model differs from Penn Resiliency, Ready model orientation on developing psychosocial aspects than therapy of emotional or behavioral disorders, but yet on the cognitive behavioral approach (Burton et al., 2010). In addition, the FRIENDS program also showed effectiveness in handling the students' fears, anxieties and upsets through develop emotional resilience and self-esteem (Matsumoto \& Shimizu, 2016; Pereira, Marques, Russo, Barros, \& Barrett, 2014; Ruttledge et al., 2016). The FRIENDS program focus on symptoms or behaviors that reflect the psychological problems, such as depression, frustration, drug addiction, and the eating disorder.

The SMART-Resilience Program focus on measured on develop of the positive attributes of students' psychological conditions. Therefore the findings of this study can a support to establish the counseling or therapy model in cognitive-behavior psychology. It can benefit, not only to manage the 
psychological problems or distress but also to develop the positive aspects of students, for instance, resilience, happiness and psychological well being (Bannink, 2014; Padesky \& Mooney, 2012).

The SMART-Resilience Model provides answers to questions that arise from the results of previous studies about the comparison of the effectiveness of cognitive behavioral counseling and strengths based counseling by Suranata, et al. (Suranata, Atmoko, \& Hidayah, 2017). Although both models are effective, the study recommends integration between the two models as an eclectic model. Based on the recommendations of the research results, to complete each of the limitations of both, both models need to complement. We can see this from the good acceptance of this Smart-Resilience model from the taking part students and also the school counselor who facilitates the students to implement the program.

The results also found that the Smart-Resilience model is effective in students in urban schools, urban queues and out of town. The results of the highest increase in resilience scores occurred in the group of participant students who were in the suburb school area. The results showed that students at rural areas could not implemented all the procedure of the program by independently after eight of 45 minutes session. Future studies need to investigate more deftly about factor areas for the Smart-Resilience program. This study is a pilot study, which has several research limitations that must be considered when interpreting the results. The pilot study, which aims to examine the feasibility of a program in a school environment in the province of Bali, Indonesia, involves only three schools recruited for this study. The participants of this study is limited, involved 15 students in each school. In addition, this study also did not involve groups of control students. Future studies need to involve comparative participant groups to see student development that is not involved in Smart-Resilience interventions or is involved with other comparable intervention programs. To ensure that the findings of this study can be generalized, it is important to evaluate the program in a wider range of students and schools. Such studies will also benefit more if the model evaluation of each procedure is carried out separately evaluating each technique and module rather than just the whole of the program.

\section{Conclusion}

The results showed that (1) the SMART-resilience program is effective for students in urban, suburb, and rural secondary school areas, (2) there are differences in the effectiveness for students in urban, suburb and rural school areas. We got the highest effectiveness in the student groups in the suburbs, (3) the program achieved high acceptance and feasibility from the school counselors and the students.

\section{Acknowledgments}

This research was supported by the Ministry of Research, Technology, and Higher Education Research (Kemenristek-Dikti) of the Republic of Indonesia in the DRPM grant of years 2019.

\section{References}

Bannink, F. (2014). Are you ready for positive cognitive behavioral therapy? Kiperonline Academic, 1(2), 65-73. Retrieved from http://journalofhappiness.net/article/are-you-ready-for-positive-cognitivebehavioral-therapy

Bannink, F. P. (2014). Positive CBT: From reducing distress to building success. Journal of Contemporary Psychotherapy, 44(1), 1-8. https://doi.org/10.1007/s10879-013-9239-7

Burton, N. W., Pakenham, K. I., \& Brown, W. J. (2010). Feasibility and effectiveness of psychosocial resilience training: A pilot study of the READY program. Psychology, Health \& Medicine, 15(3), 266-277. https://doi.org/10.1080/13548501003758710

Challen, A. R., Machin, S. J., \& Gillham, J. E. (2014). The UK Resilience Programme: a school-based universal nonrandomized pragmatic controlled trial. Journal of Consulting and Clinical Psychology, 82(1), 75-89. https://doi.org/10.1037/a0034854

Cherkin, D. C., Sherman, K. J., Balderson, B. H., Cook, A. J., Anderson, M. L., Hawkes, R. J., ... Turner, J. A. (2016). Effect of Mindfulness-Based Stress Reduction vs Cognitive Behavioral Therapy or Usual Care on Back Pain and Functional Limitations in Adults With Chronic Low Back Pain A Randomized Clinical Trial. Original Investigation, 315(12), 1240-1249. https://doi.org/10.1001/jama.2016.2323

Cutuli, J. J., Desjardins, C. D., Herbers, J. E., Long, J. D., Heistad, D., Chan, C.-K., ... Masten, A. S. 
(2013). Academic achievement trajectories of homeless and highly mobile students: resilience in the context of chronic and acute risk. Child Development, 84(3), 841-857. https://doi.org/10.1111/cdev.12013

Cutuli, J. J., Gillham, J. E., Chaplin, T. M., Reivich, K. J., Seligman, M. E. P., Gallop, R. J., ... Freres, D. R. (2013). Preventing adolescents' externalizing and internalizing symptoms: Effects of the Penn Resiliency Program. The International Journal of Emotional Education, 5(2), 67-79. Retrieved from http://www.ncbi.nlm.nih.gov/pmc/articles/PMC3952879/\%5Cnhttp://0search.proquest.com.pugwash.lib.warwick.ac.uk/docview/1520888657?accountid=14888\%5Cnhttp :// pugwash.lib.warwick.ac.uk:4550/resserv?genre=article\&issn=2073-

7629\&title $=$ The + International + Journal

Dameron, M. L. (2016). Person-Centered Counseling and Solution-Focused Brief Therapy: An Integrative Model for School Counselors. Journal of School Counseling, 14(10).

Dray, J., Bowman, J., Freund, M., Campbell, E., Wolfenden, L., Hodder, R. K., \& Wiggers, J. (2011). Improving adolescent mental health and resilience through a resilience-based intervention in schools: study protocol for a randomised controlled trial. https://doi.org/10.1186/1745-6215-15289

Durlak, J. A., Weissberg, R. P., Dymnicki, A. B., Taylor, R. D., \& Schellinger, K. B. (2011). The impact of enhacing students' social and emotional learning: A meta-analysis of school-based universal interventions. Child Development, 82(1), 405-432. https://doi.org/10.1111/j.14678624.2010.01564.x

Field, A. (2009). Discovering statistics using SPSS. Sage publications.

Gillham, J. E., Reivich, K. J., Brunwasser, S. M., Freres, D. R., Chajon, N. D., Kash-MacDonald, V. M., ... Seligman, M. E. P. (2012). Evaluation of a Group Cognitive-Behavioral Depression Prevention Program for Young Adolescents: A Randomized Effectiveness Trial. Journal of Clinical Child \& Adolescent Psychology, 41(5), 621-639. https://doi.org/10.1080/15374416.2012.706517

Goss-Sampson, M. A. (2019). Statistical ANALYSIS IN JASP: A Guide For Students.

Hair, J. F., Black, W. C., Babin, B. J., \& Anderson, R. E. (2010). Multivariate Data Analysis. Vectors. https://doi.org/10.1016/j.ijpharm.2011.02.019

Hodder, Rebecca K, Freund, M., Bowman, J., Wolfenden, L., Campbell, E., Wye, P., ... Wiggers, J. (2012). A cluster randomised trial of a school-based resilience intervention to decrease tobacco, alcohol and illicit drug use in secondary school students: study protocol. BMC Public Health. https://doi.org/10.1186/1471-2458-12-1009

Hodder, Rebecca Kate, Freund, M., Wolfenden, L., Bowman, J., Gillham, K., Dray, J., \& Wiggers, J. (2014). Systematic review of universal school-based resilience interventions targeting adolescent tobacco, alcohol or illicit drug use: review protocol. BMJ Open, 4(5). https://doi.org/10.1136/bmjopen-2013-004718

Hodder, Rebecca Kate, Freund, M., Wolfenden, L., Bowman, J., Nepal, S., Dray, J., ... Wiggers, J. (2017). Systematic review of universal school-based 'resilience' interventions targeting adolescent tobacco, alcohol or illicit substance use: A meta-analysis. Preventive Medicine. https://doi.org/10.1016/j.ypmed.2017.04.003

Kim, J. S., \& Franklin, C. (2009). Solution-focused brief therapy in schools: A review of the outcome literature. Children and Youth Services Review, 31(4), 464-470. https://doi.org/10.1016/j.childyouth.2008.10.002

Kurniastuti, I., \& Azwar, S. (2016). Constructtion of Student Well-being Scale for 4-6th Graders. Jurnal Psikologi, 41(1), 1. https://doi.org/10.22146/jpsi.6954

Leppin, A. L., Bora, P. R., Tilburt, J. C., Gionfriddo, M. R., Zeballos-Palacios, C., Dulohery, M. M., ... Montori, V. M. (2014). The efficacy of resiliency training programs: A systematic review and metaanalysis of randomized trials. PLoS ONE, 9(10). https://doi.org/10.1371/journal.pone.0111420

Lewinsohn, P. M., Hops, H., Roberts, R. E., Seeley, J. R., \& Andrews, J. A. (1993). Adolescent psychopathology: I. Prevalence and incidence of depression and other DSM-III-R disorders in high school students. Journal of Abnormal Psychology, 102(1), 133.

Martínez-Martí, M. L., \& Ruch, W. (2017). Character strengths predict resilience over and above positive affect, self-efficacy, optimism, social support, self-esteem, and life satisfaction. Journal of Positive Psychology, 12(2). https://doi.org/10.1080/17439760.2016.1163403

Matsumoto, Y., \& Shimizu, E. (2016). The FRIENDS Cognitive Behavioral Program in Japanese schools: An examination of the treatment effects. School Psychology International, 37(4), 397-409. https://doi.org/10.1177/0143034316649639 
Mongrain, M., \& Anselmo-Matthews, T. (2012). Do Positive Psychology Exercises Work? A Replication of Seligman et al. Journal of Clinical Psychology, 68(4), 382-389. https://doi.org/10.1002/jclp.21839

Padesky, C. A., \& Mooney, K. A. (2012). Strengths-Based Cognitive-Behavioural Therapy: A Four-Step Model to Build Resilience. Clinical Psychology and Psychotherapy, 19(4), 283-290. https://doi.org/10.1002/cpp.1795

Pereira, A. I., Marques, T., Russo, V., Barros, L., \& Barrett, P. (2014). Effectiveness of the friends for life program in portuguese schools: Study with a sample of highly anxious children. Psychology in the Schools. https://doi.org/10.1002/pits.21767

Ruttledge, R., Devitt, E., Greene, G., Mullany, M., Charles, E., Frehill, J., \& Moriarty, M. (2016). A randomised controlled trial of the FRIENDS for Life emotional resilience programme delivered by teachers in Irish primary schools. Educational and Child Psychology, 33(2), 69-89.

Sagone, E., \& Caroli, M. E. De. (2013). Relationships between Resilience, Self-Efficacy, and Thinking Styles in Italian Middle Adolescents. Procedia - Social and Behavioral Sciences, 92(Lumen), 838845. https://doi.org/10.1016/j.sbspro.2013.08.763

Sagone, E., \& Elvira De Caroli, M. (2014). A Correlational Study on Dispositional Resilience, Psychological Well-being, and Coping Strategies in University Students. American Journal of Educational Research, 2(7), 463-471. https://doi.org/10.12691/education-2-7-5

Sankaranarayanan, A., \& Cycil, C. (2014). Resiliency training in Indian children: A pilot investigation of the Penn Resiliency Program. International Journal of Environmental Research and Public Health, 11(4), 4125-4139. https://doi.org/10.3390/ijerph110404125

Schulz, A., Becker, M., Van der Auwera, S., Barnow, S., Appel, K., Mahler, J., ... Grabe, H. J. (2014). The impact of childhood trauma on depression: Does resilience matter? Population-based results from the Study of Health in Pomerania. Journal of Psychosomatic Research. https://doi.org/10.1016/j.jpsychores.2014.06.008

Shoshani, A., \& Steinmetz, S. (2014). Positive Psychology at School: A School-Based Intervention to Promote Adolescents' Mental Health and Well-Being. Journal of Happiness Studies, 15(6), 12891311. https://doi.org/10.1007/s10902-013-9476-1

Suranata, K., Atmoko, A., \& Hidayah, N. (2017). Validation of Psychological Resilience Scale and Implication for Guidance and Counseling Practice. In 2nd ICET Theme:"IMPROVING THE QUALITY OF EDUCATION AND TRAINING THROUGH STRENGTHENING NETWORKING (Vol. 1, p. 467).

Suranata, K., Atmoko, A., \& Hidayah, N. (2017). Enhancing Students' Resilience: Comparing The Effect of Cognitive-Behavior And Strengths-Based Counseling. In Proceedings of the 2nd International Conference on Innovative Research Across Disciplines (ICIRAD 2017) (Vol. 134, pp. 102-108). Paris, France: Atlantis Press. https://doi.org/10.2991/icirad-17.2017.20

Suranata, K., Atmoko, A., Hidayah, N., Rangka, I. B., \& Ifdil (2017). Risks and resilience of students with hearing impairment in an inclusive school at Bengkala, Bali, Indonesia. Specialusis Ugdymas, 2(37), 165-214. https://doi.org/10.21277/se.v2i37.328

VicHealth. (2015). Interventions to build resilience among young people A literature review. VicHealth. Melbourne: Victorian Health Promotion Foundation. https://doi.org/10.1.1.45.1447

Waters, L. (2011). A Review of School-Based Positive Psychology Interventions. The Australian $\begin{array}{llll}\text { Educational and } & \text { Developmental } & \text { Psychologist, }\end{array}$ https://doi.org/10.1375/aedp.28.2.75 